\title{
Pengembangan Media Pembelajaran Sistem Bahan Bakar Diesel Inline untuk Meningkatkan Minat Belajar Pada Mahasiswa Pendidikan Teknik Otomotif Universitas Muhammadiyah Purworejo
}

\author{
Anang Fatchullutfi, Aci Primartadi \\ Program Studi Pendidikan Teknik Otomotif, Universitas Muhammadiyah Purworejo

\section{Anangke7@gmail.com}

\begin{abstract}
Abstrak
Penelitian ini bertujuan untuk (1.)Untuk mengetahui pengembangan media pembelajaran sistem bahan bakar diesel inline. (2.)Untuk mengetahui kelayakan media pembelajaran sistem bahan bakar Diesel Inline.

Penelitian ini menggunakan metode Reseach and Development $(R \& D)$ dengan subyek penelitian yang diambil adalah Dosen Universitas Muhammadiyah Purworejo, Guru SMK dan mahasiswa Jurusan Pendidikan Teknik Otomotif Universitas Muhammadiyah Purworejo.

Hasil penelitian ini diukur berdasarkan kelayakan media pembelajaran yang di validasi oleh para ahli Berdasarkan hasil validasi oleh ahli media diperoleh skor rata-rata sebesar $72.5 \%$ dengan kriteria "Cukup valid", hasil validasi oleh ahli media guru smk diperoleh skor rata-rata sebesar 83.3\% dengan kriteria "valid", dan hasil validasi oleh mahasiswa diperoleh skor rata-rata sebesar $82.5 \%$ dengan kriteria "valid" artinya media yang dikembangkan layak digunakan dan siap digunakan sebagai bahan ajar.
\end{abstract}

Kata Kunci : Media pembelajaran, Diesel inline

\section{Pendahuluan}

Perkembangan dunia pendidikan saat ini sedang memasuki era yang ditandai dengan gencarnya inovasi teknologi, sehingga menuntut adanya penyesuaian sistem pendidikan yang selaras dengan tuntutan dunia kerja. Pendidikan merupakan sarana yang tepat untuk menyiapkan tenaga kerja, bekal di masa depan dan juga membentuk warga negara yang baik sehingga pendidikan mengemban fungsi yang sangat penting.

Menurut Pavlova, 2009:7 dalam (Suyitno, 2016) pendidikan kejuruan adalah pendidikan yang mempelajari pelatihan secara spesifik yang dapat digunakan dalam dunia kerja. Sedangkan Prosser dan Quekqly, 1950:2 dalam (Suyitno, 2016) memaparkan pendidikan kejuruan merupakan sebuah konsep pengalaman yang menyeluruh bagi setiap individu yang belajar untuk kesuksesan dunia kerja. Dalam hal ini, pendidikan kejuruan banyak belajar tentang persiapan-persiapan sebelum terjun ke dunia kerja. Pembelajaran tersebut meliputi 
pembelajaran kognitif, afektif, dan psikomotorik. Pendidikan kejuruan adalah pendidikan yang berorientasi pada pengembangan proses dan hasil dari pembelajaran.

Menurut Wina Sanjaya ( 2006:2) didalam undang-undang No. 20 tahun 2003 tentang pendidikan Nasional menyatakan bahwa pendidikan adalah usaha sadar dan terencana untuk mewujudkan suasana belajar dan proses pembelajaran agar peserta didik secara aktif mengembangkan potensi dirinya untuk memiliki kekuatan spiritual keagamaan, pengendalian diri, kepribadian, kecerdasan, akhlak mulia, serta ketrampilan yang diperlukan dirinya, masyarakat, bangsa, dan negara.

Oleh sebab itu, pendidikan merupakan kebutuhan yang sangat penting bagi individu, masyarakat, dan negara dalam meningkatkan sumber daya manusia. Sejalan dengan itu maka perhatian terhadap perkembangan dunia pendidikan haruslah ditingkatkan. Salah satu faktor yang mempengaruhi kualitas pendidikan yaitu keberhasilan dalam kegiatan pembelajaran

Penelitian ini bertujuan untuk (1.)Untuk mengetahui pengembangan media pembelajaran sistem bahan bakar diesel inline. (2.)Untuk mengetahui kelayakan media pembelajaran sistem bahan bakar Diesel Inline.

Oleh karena itu, peneliti mengangkat judul "Pengembangan Media Pembelajaran Sistem Bahan Bakar Diesel Inline Untuk Meningkatkan Minat Belajar Pada Mahasiswa Pendidikan Teknik Otomotif Universitas Muhammadiyah Purworejo".

\section{Metode Penelitian}

Penelitian ini menggunakan desain penelitian dan pengembangan atau Research and Development model (Borg and Gall) karena metode penelitian yang digunakan untuk menghasilkan produk tertentu, dan menguji keefektifan produk tersebut. Terdapat 10 langkah utama dalam prosedur penelitian dan pengembangan ini. Adapun dari penelitian dan pengembangan mengunakan 8 langkah disebabkan tidak memproduksi dalam jumlah banyak.

\section{Tempat Dan Waktu Penelitian}

1. Tempat penelitian : penelitian sekaligus sebagai tempat pengambilan data penelitian yang dilaksanakan di Universitas Muhammadiyah Purworejo. 
2. Waktu penelitian : waktu pelaksaan penelitian ini mulai pada bulan September 2020 s.d. Selesai.

\section{Teknik Pengumpulan Data}

Pengumpulan data pada penelitian ini menggunakan observasi, angket dan dokumentasi. Menurut Suyitno (2018 :114), Ada dua cara yang dapat dipakai untuk mengumpulkan data, yaitu: 1) observasi atau wawancara meliputi wawancara dengan dosen pengajar, 2) Angket digunakan untuk menilai uji coba produk yang dihasilkan yaitu berupa media pembelajaran bahan bakar Diesel Inline.

\section{Hasil Pembahasan}

Pengembangan media pembelajaran dilakukan berdasarkan studi pendahuluan. Proses penyusunan dilakukan melalui pengumpulan materi melalui referensi yang relevan. Pengembangan media pembelajaran ini melalui tahap validasi yaitu validasi ahli materi dan validasi ahli media :

\begin{tabular}{|c|c|c|c|}
\hline & tabel hasil Valic & Media Dosen, Gu & dan Mahasiswa \\
\hline Pilihan & Dosen & Guru Smk & Mahasiswa \\
\hline Total Skor(SM) & 29 & 37 & 36 \\
\hline (R) & 40 & 40 & 40 \\
\hline (\%) & 72,5 & 83,3 & 82,5 \\
\hline Kriteria & VALID & VALID & VALID \\
\hline
\end{tabular}

Analisis data hasil validasi menunjukan kelayakan media bahan bakar Diesel Inline. dari ahli media Dosen dengan presentase 72,5\%, Guru SMK dengan presentase 83,3\%. dan Mahasiswa dengan presentase 82,5\%. Nilai tersebut termasuk dalam kriteria "valid".". Sehingga media pembelajan dapat diujicobakan ke lapangan. 
Berdasarkan hasil validasi media menunjukan

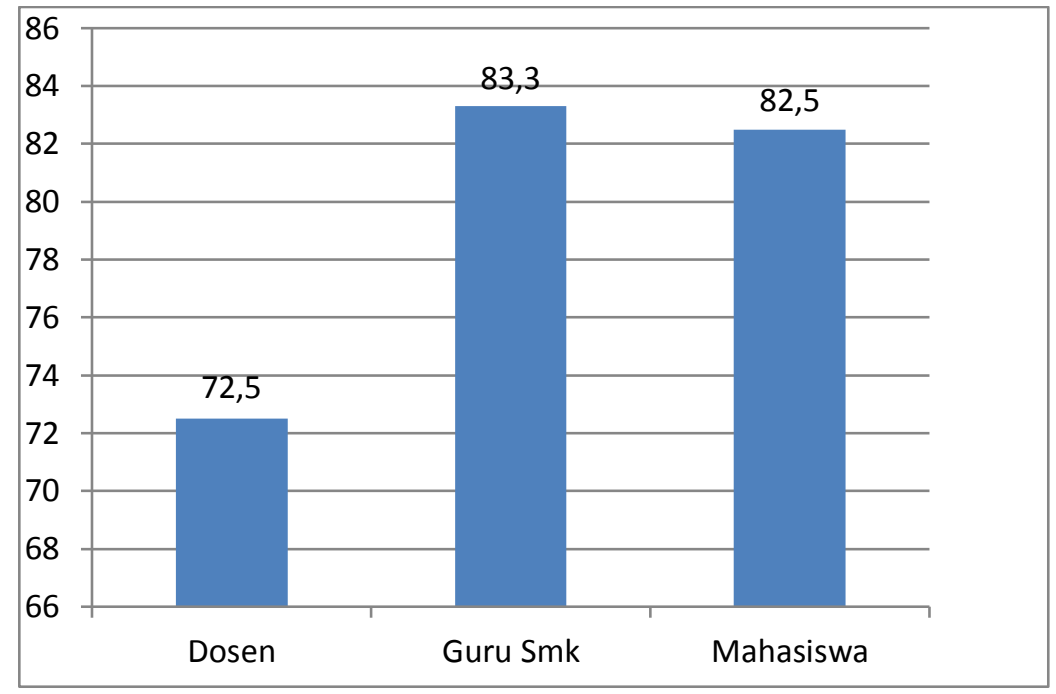

Berdasarkan Hasil validasi dari Dosen, Guru Smk dan Mahasiswa disajikan dalam diagram batang

\section{Kesimpulan}

Dari hasil penelitian dan pengembangan ini maka Proses pembuatan pengembangan media pembelajaran sistem bahan bakar diesel inline berupa stand dan berdasarkan analisis masalah dan kebutuhan dihasilkan media pembelajaran media sistem aliran bahan bakar diesel inline yang siap pakai. Tahap pengembangan media pembelajaran motor diesel pada mahasiswa Pendidikan Teknik Otomotif Universitas Muhammadiyah Purworejo telah meliputi pencarian potensi masalah, pengumpulan informasi, desain produk, validasi desain, perbaikan desain, ujicoba produk, pengujian produk, ujicoba pemakaian dan revisi produk.

Hasil validasi ahli media nilai presentase sebesar $72.5 \%$ (cukup valid). Dari hasil penilaian tersebut menunjukkan produk layak (baik) digunakan sebagai media pembelajaran.

Hasil ujicoba kelompok validasi guru dan mahasiswa diperoleh $83.3 \%$ dan $82.5 \%$ (valid).

Melihat hasil dari validasi ahli media, Guru SMK dan mahasiswa. Media pembelajaran Diesel Inline dapat digunakan dalam pembelajaran sebagai media untuk meningkatkan minat belajar mahasiswa teknik otomotif di Universitas Muhammadiyah Purworejo. 


\section{Saran}

Agar produk yang dihasilkan bisa dimanfaatkan secara maksimal dalam kegiatan pembelajaran, maka ada beberapa saran yang terkait dengan media pembelajaran antara lain :

1. Bagi Dosen

Diharapkan dosen selayaknya bisa mengembangkan produk-produk yang baik melalui penelitian sehingga akan meningkatkan minat belajar.

2. Bagi lembaga diharapkan memfasilitasi dosen untuk menghasilkan media yang belum tersedia agar proses perkuliahan yang dibutuhkan terpenuhi.

3. Bagi peneliti berikutnya, agar lebih kreatif serta menemukan ide-ide baru dalam pembuatan media pembelajaran, sehingga akan meningkatkan minat belajar mahasiswa.

\section{Daftar Pustaka}

Aji, P., Primartadi, A., \& Suyitno, S. (2021). Menentukan Kapasitas Motor Brushless Direct Current sebagai Penggerak Mobil Listrik. Auto Tech: Jurnal Pendidikan Teknik Otomotif Universitas Muhammadiyah Purworejo, 16(1),

http://jurnal.umpwr.ac.id/index.php/autotech/article/view/875

Ardiyansah, N. I., \& Suyitno, S. (2019). PENGEMBANGAN MODUL PEMBELAJARAN KELISTRIKAN OTOMOTIF UNTUK MENINGKATKAN MINAT DAN HASIL BELAJAR DI SMK A YANI GEBANG PURWOREJO. Auto Tech: Jurnal Pendidikan Teknik Otomotif Universitas Muhammadiyah Purworejo, 13(02).

http://ejournal.umpwr.ac.id/index.php/autotext/article/view/5400/4938

Anggoro, Y., \& Suyitno, S. (2019). PENGARUH PELAKSANAAN PRAKTIK INDUSTRI DAN MINAT WIRAUSAHA DENGAN KESIAPAN MENTAL KERJA SISWA KELAS XII JURUSAN TEKNIK SEPEDA MOTOR SMK MUHAMMADIYAH 1 TEMON. Auto Tech: Jurnal Pendidikan Teknik Otomotif Universitas Muhammadiyah Purworejo, 13(02). http://ejournal.umpwr.ac.id/index.php/autotext/article/view/5395/4933

Sumanang, Y. P., Suyitno, S., \& Sudarsono, B. (2020, May). The Influence of Learning Style and Creativity Toward Student Achievement Index. In INTERNATIONAL CONFERENCE ON EDUCATION (Vol. 2, No. 1). http://eproceedings.umpwr.ac.id/index.php/ice/article/view/1155/1059

Sanjaya, W. 2012. Strategi Pembelajaran. Jakarta: Kencana Prenada Media Groub

Sugiyono, Metode PenelitianKuantitatif, Kualitatif, Dan R\&D, Alfabeta, Bandung, 2016.

Susanto, A., \& Suyitno, S. (2021). Penerapan Metode Pembelajaran Demonstrasi pada Mata Pelajaran K3 untuk Meningkatkan Hasil Belajar Siswa. Auto Tech: Jurnal Pendidikan Teknik Otomotif 
Universitas

Muhammadiyah

Purworejo, 16(1),

14-21.

http://jurnal.umpwr.ac.id/index.php/autotech/article/view/876

Suyitno, S., Pardjono, P., \& Sofyan, H. (2017). Work Based Learning Terintegrasi Konsep, strategi dan implementasi dalam pendidikan kejuruan.

Suyitno, S. (2014). Sistem Pemindah Tenaga (SPT) Otomotif. Danadyaksa. Yogyakarta.

Suyitno, S., Widianto, I., \& binti Masrul, S. (2018). Development of learning media for the course of two-stroke gasoline motors to improve students' learning outcomes. Jurnal Pendidikan Teknologi dan Kejuruan, 24(1), 83-90. https://journal.uny.ac.id/index.php/iptk/article/view/18008/10719

Suyitno, S. (2018). Penelitian Tindakan Kelas, Eksperimen dan R \& D. Alfabeta. Bandung. 